\title{
Clinical experience with single-port access laparoscopic cystectomy and myomectomy
}

\author{
Jae-Hyeok Jeong' ', Yu-Ri Kim ', Kil-Pyo Hong' ', Jae-Eun Ha', Eun-Jeong Kim', Da-Kyo Hong' , Kyu-Sup Lee² \\ 'Department of Obstetrics and Gynecology, Hwamyeong Ilsin Christian Hospital, Busan; ${ }^{2}$ Department of Obstetrics and Gynecology, Pusan National \\ University School of Medicine, Busan, Korea
}

Objective: This study was performed to assess our clinical experience with single-port access (SPA) laparoscopic cystectomy and myomectomy and the surgical outcomes of those procedures at our institution.

Methods: The authors evaluated the surgical outcomes of SPA laparoscopic cystectomy in 293 patients and SPA laparoscopic myomectomy in 246 patients. The surgical outcomes comprised operation time, the amount of blood loss during the operation, the change in hemoglobin (before and after the operation), the change in hematocrit (before and after the operation), switching to the multi-port access method, complications, transfusions, and the duration of the postoperative hospital stay.

Results: The Pearson correlation coefficient and the Spearman correlation coefficient between the operation time and the amount of blood loss were 0.312 and 0.321 for SPA laparoscopic cystectomy, respectively, and 0.706 and 0.674 for SPA laparoscopic myomectomy, respectively. The drops in hemoglobin and hematocrit were $1.33 \pm 0.78 \mathrm{~g} / \mathrm{dL}$ and $4.14 \% \pm 2.45 \%$, respectively, in SPA laparoscopic cystectomy, while the corresponding figures were $1.34 \pm 1.13 \mathrm{~g} / \mathrm{dL}$ and $4.17 \% \pm 3.24 \%$ in SPA laparoscopic myomectomy, respectively.

Conclusion: This study reported the surgical outcomes of SPA laparoscopic cystectomy and myomectomy and compared them to previously published findings on traditional laparoscopic cystectomy and myomectomy. No significant differences were found in the surgical outcomes between SPA and traditional laparoscopic cystectomy and myomectomy.

Keywords: Cystectomy; Laparoscopy; Minimally invasive surgical procedures; Single port; Squamous intraepithelial lesions of the cervix; Uterine myomectomy

\section{Introduction}

Ovarian cystectomy and myomectomy are the two most frequently performed gynecologic operations in reproductive-age women. Benign ovarian cysts mostly occur in reproductive-age women, for whom it is important to have the majority of the ovarian tissue preserved after surgery. In order to preserve the maximum ovarian re-

Received: Mar 26, 2015 · Revised: Nov 13, 2015 · Accepted: Dec 1, 2015 Corresponding author: Kyu-Sup Lee

Department of Obstetrics and Gynecology, Pusan National University School of Medicine, 20 Geumo-ro, Mulgeum-eup, Yangsan 50612, Korea

Tel: +82-55-360-2580 Fax:+82-55-360-2160 E-mail: kuslee@pusan.ac.kr

* This work was supported by a clinical research grant from Pusan National University Hospital in 2016.

This is an Open Access article distributed under the terms of the Creative Commons Attribution Non-Commercial License (http://creativecommons.org/licenses/by-nc/3.0/) which permits unrestricted non-commercial use, distribution, and reproduction in any medium, provided the original work is properly cited. serve, laparoscopic ovarian cystectomy is generally preferred. The lifetime incidence of uterine myoma is approximately $20 \%$ to $25 \%$, and it is the most common benign tumor in reproductive-age women. Surgery is performed on women who suffer from menorrhagia, dysmenorrhea, or increase in size of the fibroid [1]. The utility of laparoscopic myomectomy has been well established among symptomatic reproductive-age women with myoma [2,3], and previous studies have found no difference in the duration of surgery, the amount of blood loss during surgery, or the incidence of postoperative adhesion in comparison with open surgery $[4,5]$. Likewise, no difference was found between laparoscopic myomectomy or open myomecto$\mathrm{my}$ in the rate of postoperative uterine rupture [6]. In infertile patients, myomectomy has been shown to lead to a significant improvement in the pregnancy rate $[7,8]$. Currently, single-port access (SPA) laparoscopic myomectomy is performed as a minimally invasive surgical technique $[9,10]$. SPA laparoscopic surgery is superior to 
multi-port laparoscopic surgery in terms of cosmetic outcomes and postoperative pain relief and recovery, but due to the difficulty in the suture technique, hemostasis is more challenging and it generally is more time-consuming [11].

In this study, we share our clinical experience with SPA laparoscopic ovarian cystectomy and myomectomy performed in our hospital.

\section{Methods}

The candidates for this study were 869 women who received SPA laparoscopic surgery in the gynecologic department of Hwamyeong Ilsin Christian Hospital between October 2011 and December 2014. The study ultimately included 246 patients who underwent SPA laparoscopic myomectomy and 293 patients who underwent SPA laparoscopic ovarian cystectomy.

Women who received both SPA laparoscopic ovarian cystectomy and myomectomy at once were classified into the SPA laparoscopic myomectomy group in order to avoid duplication. This study was approved by the institutional review board of our hospital. All of the operations were performed by one of seven doctors.

A retrospective review of each patient's medical records was performed. The following information was collected about each subject: age; body mass index (BMI); parity; operative history; preoperative diagnosis; the size of the ovarian cyst; the preoperative diagnosis of the ovarian cyst; the location of the myoma; the weight, size, and quantity of the myoma(s); the usage of a morcellator during surgery; the suture technique; the type of surgery (e.g., removal of a single myoma, removal of multiple myomas, or other adjuvant surgery); the duration of surgery; blood loss during surgery; conversion to multiport laparoscopic surgery; endometrial opening in the peritoneal cavity; changes in hemoglobin and hematocrit levels from baseline to after the operation; blood transfusions; complications; the pathological report; and the duration of the postoperative hospital stay.

The operative time was defined as the time from the umbilical incision to the completion of the skin suture. The final measurements of hemoglobin and hematocrit prior to surgery were defined as the preoperative values, and the same measurements on the first day following surgery were defined as the postoperative values.

The degree of adhesion was defined as follows: slight adhesion in the mesentery was defined as grade l; adhesion formation in the uterus or adnexa as grade Il; adhesion between the bowel and the uterine adnexa as grade III; and adhesion causing the obstruction of the pouch of Douglas as grade IV. Blood loss during surgery was calculated by the subtraction of irrigated fluid from the suctioned fluid. We only included surgical complications that required additional treatment: fever for more than 5 days, urogenital problems, intestinal injury, intraperitoneal hematoma, the need for transfusion, and reoperation.
The duration of the postoperative hospital stay was classified into four categories: 7 days or less, 8 to 10 days, 11 to 14 days, or 15 days or more.

\section{Surgical procedure}

A standardized protocol was followed for preoperative care, according to which each patient received prophylactic antibiotics $30 \mathrm{~min}$ utes prior to surgery. General anesthesia was performed in the dorsal lithotomy position, and a uterine elevator (Koh Colpotomizer, ColpoPneumo Occluder, RUMI, Cooper Surgical, Trumbull, CT, USA) was inserted. SPA was achieved using the following technique. A 2 to 2.5$\mathrm{cm}$ vertical incision was made, and the fascia was then incised after elevating it with Kelly clamps. The peritoneum was incised after confirming the absence of intestinal adhesion. An Octo-Port (DalimsurgNET, Seoul, Korea) device was then inserted into the single port.

The rest of the surgical procedure was identical to that of multi-port laparoscopic surgery. Carbon dioxide was infused with a pressure of 12 $\mathrm{mm} \mathrm{Hg}$, and a 5-mm wide, 45-cm-long laparoscope (Karl Storz, Tuttlingen, Germany) was inserted to inspect the presence, location, and size of the ovarian cysts and myomas. The general principle was to remove ovarian cysts without rupturing them. All myomas larger than $2 \mathrm{~cm}$ were removed. Straight instruments with a length of $43 \mathrm{~cm}$, identical to those utilized in multi-port laparoscopic surgery, were used in most procedures, but curved instruments were also used. In order to reduce hemorrhage from the myomas, an injection of $20 \mathrm{IU}$ of vasopressin (vasopressin injection, $20 \mathrm{IU} / 1 \mathrm{ML}$; Hanlim Pharmaceuticals, Cheongju, Korea) was made into the incision before the removal of the myomas. Myomectomy was performed using monopolar and bipolar electrocautery. Electrocautery was used minimally in order to reduce the amount of injury to the ovaries after removing the ovarian cysts, and sutures were preferred. A figure-of-eight primary suture was placed after the removal of myomas close to the endometrium, followed by a secondary suture for apposition of the myometrium and serosal layers. When myomas were located on external layers, only one layer of suturing was performed on the myometrial and serosal layers. A two-layer suture was performed in women expecting future pregnancy. Either interrupted or continuous locking sutures were used by the surgeons when performing the figure-of-eight sutures. When interrupted figureof-eight sutures were performed, a knot pusher (Wisap, Brunnthal/Hofolding, Germany) was used for extracorporeal tying. An intracorporeal tie was used in the continuous sutures (Figures 1, 2). Either 1-0 or 2-0 absorbable sutures (Polysorb, Covidien, Dublin, Ireland) were used. The ovarian cysts that were removed were carried out through the umbilicus using the Endopouch specimen retrieval bag (Ethicon, Somerville, $\mathrm{NJ}$, USA). Myomas larger than $3 \mathrm{~cm}$ were removed after further division of the specimen, while myomas smaller than $3 \mathrm{~cm}$ were removed without such a procedure. The use of a morcellator (Electrical Morcellator, 

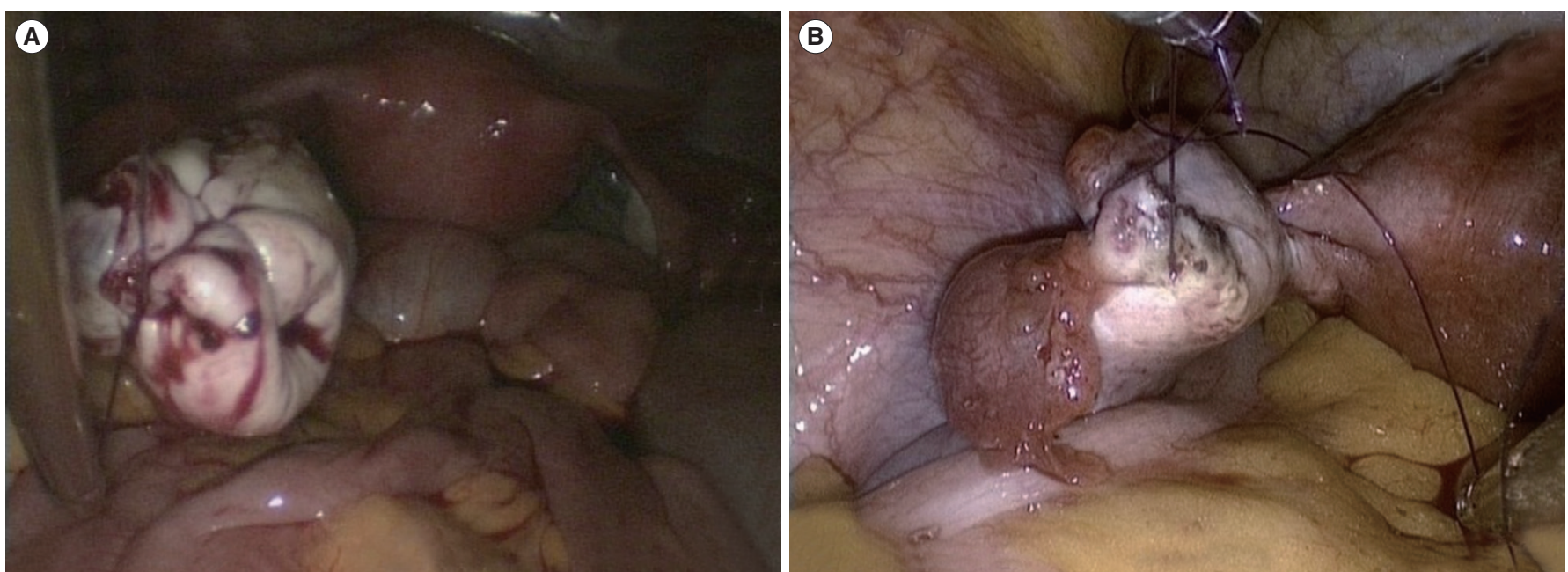

Figure 1. (A) Interrupted suture technique in a figure-of-eight and (B) continuous locking technique in single-port access laparoscopic cystectomy.
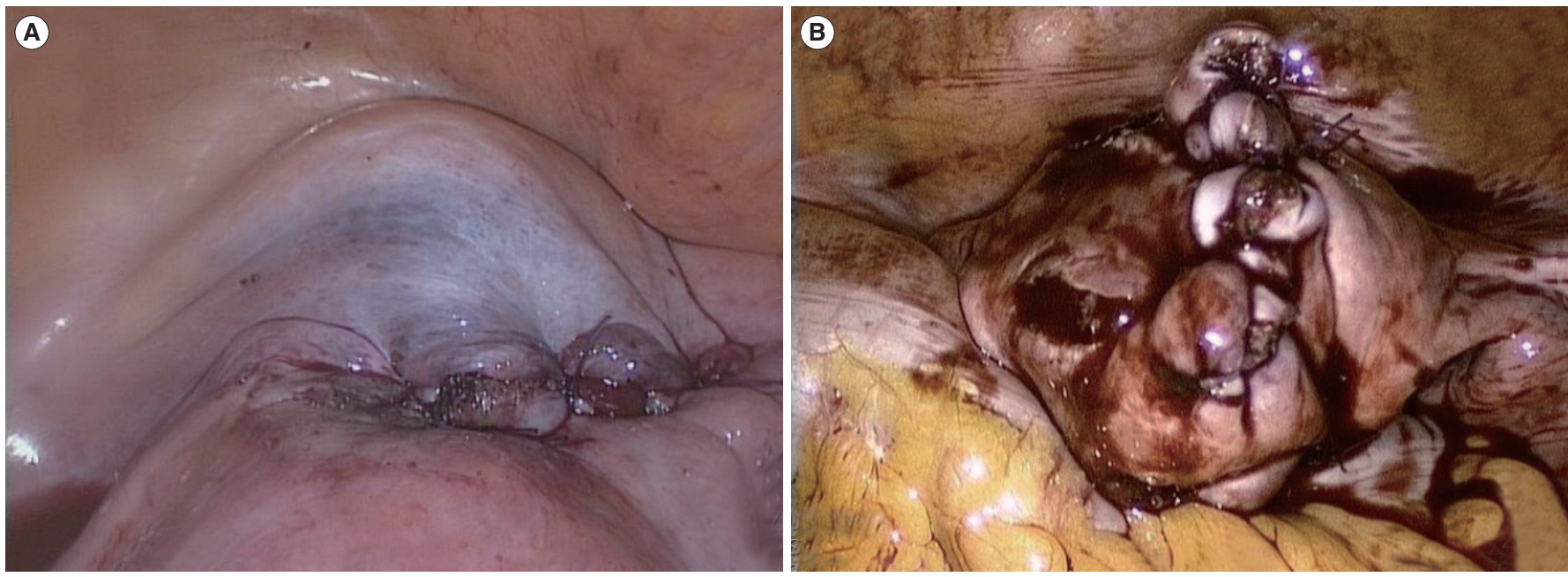

Figure 2. (A) Interrupted suture technique in a figure-of-eight and (B) continuous locking technique in single-port access laparoscopic myomectomy.

Gynecare, Ethicon) was avoided whenever possible. A drainage tube was left in place through the umbilicus after surgery. After myomectomy, uterine contractile agents (Duratocin injection, $100 \mu \mathrm{g} / 1 \mathrm{~mL}$; Ferring Pharm, Saint-Prex, Swiss) or methylergometrine maleate (Eruvin injection, 0.2 mg/1 mL; Daewon Pharm, Seoul, Korea) were used.

\section{Statistical analysis}

Statistical analysis was performed using SPSS ver. 18.0 (SPSS Inc., Chicago, IL, USA). The $p$-values less than 0.05 , as calculated using the chi-square test or Fisher's exact test, were considered to indicate statistical significance.

\section{Results}

The age of the 293 patients in our study ranged from 13 to 74 years (mean, 35.2 years) (Table 1). The mean BMl was $21.85 \pm 2.95 \mathrm{~kg} / \mathrm{m}^{2}$. A total of 67 patients had previously received surgical interventions. Twenty-seven women (9.8\%) had a previous history of one Caesarean delivery (9.2\%), 18 (6.1\%) had undergone two or more Caesarean deliveries, two had a history of myomectomy, 12 had a history of adnexa surgery, three had a history of appendectomy, and one had a history of other abdominal surgery.

The mean diameter of the ovarian cysts was $5.34 \pm 2.92 \mathrm{~cm}$. The preoperative diagnoses of the ovarian cysts were teratoma $(n=135$, $46.1 \%)$, endometrioma $(n=90,30.7 \%)$, solid tumor $(n=46,15.7 \%)$, and other ovarian cyst $(n=22,7.5 \%)$.

The mean age of the women who received SPA laparoscopic surgery was 39.9 years (range, 23-57 years) (Table 2). Their mean BMI was $22.78 \pm 3.35 \mathrm{~kg} / \mathrm{m}^{2}$, and 61 patients had a history of surgery. A total of 16 women (6.5\%) had experienced one Caesarean delivery; 
Table 1. Clinical characteristics of the 293 patients who underwent single-port access cystectomy

\begin{tabular}{lc}
\hline Characteristic & Variable \\
\hline Age $(\mathrm{yr})$ & $35.23 \pm 10.69$ \\
Body mass index $\left(\mathrm{kg} / \mathrm{m}^{2}\right)$ & $21.85 \pm 2.95$ \\
No. of previous abdominal operations & $0.35 \pm 0.74$ \\
Previous abdominal surgery type & \\
Caesarean section (once) & $27(9.2)$ \\
Caesarean section (twice or more) & $18(6.1)$ \\
Myomectomy & $2(0.7)$ \\
Adnexal operation & $12(4.1)$ \\
Appendectomy & $3(1.0)$ \\
Bilateral tubal ligation & 0 \\
Diagnostic laparoscopy & 0 \\
Other abdominal surgery & $1(0.3)$ \\
Combined surgery & $0(0.0)$ \\
Size of ovarian tumor (cm) & $5.34 \pm 2.92$ \\
Suspected preoperative diagnosis & \\
Mature cystic teratoma & $135(46.1)$ \\
Endometriosis & $90(30.7)$ \\
Other benign tumor & $46(15.7)$ \\
Solid tumor & $22(7.5)$
\end{tabular}

Values are presented as mean \pm standard deviation or number (\%).

${ }^{a}$ Mucinous cystadenoma, serous cystadenoma, other benign cyst, etc.; ${ }^{\text {b) }} \mathrm{Fi}-$ broma, sex-cord tumor.

Table 2. Clinical characteristics of the 246 patients who underwent single-port access myomectomy

\begin{tabular}{lc}
\hline Characteristic & Variable \\
\hline Age $(\mathrm{yr})$ & $39.94 \pm 6.48$ \\
Body mass index $\left(\mathrm{kg} / \mathrm{m}^{2}\right)$ & $22.78 \pm 3.35$ \\
No. of previous abdominal operations & $1.74 \pm 0.44$ \\
Previous abdominal surgery type & \\
Caesarean section (once) & $71(8.2)$ \\
Caesarean section (twice or more) & $82(9.4)$ \\
Myomectomy & $6(0.7)$ \\
Adnexal operation & $19(2.2)$ \\
Bilateral tubal ligation & $2(0.2)$ \\
Diagnostic laparoscopy & $2(0.2)$ \\
Appendectomy & $11(1.3)$ \\
Other abdominal surgery & $4(0.5)$ \\
Combined surgery & $23(2.6)$ \\
Size of myoma by ultrasonogram (cm) & $5.89 \pm 2.67$ \\
Myoma type & \\
Intramural & $14(5.7)$ \\
Subserosal & $2(0.8)$ \\
Submucosal & $3(1.2)$ \\
Combined & $227(92.3)$ \\
\hline
\end{tabular}

Values are presented as mean \pm standard deviation or number (\%).

26 (10.6\%) had undergone two Caesarean deliveries; two had a history of myomectomy; one had a history of adnexal surgery; five had undergone appendectomy; two had a history of bilateral tubal liga-
Table 3. Clinical outcomes of single-port access laparoscopic cystectomy

\begin{tabular}{|c|c|}
\hline Clinical outcome & Variable \\
\hline \multicolumn{2}{|l|}{ Suture method } \\
\hline Interrupted & $173(59.0)$ \\
\hline Continuous locking & $120(41.0)$ \\
\hline \multicolumn{2}{|l|}{ Adhesion degree } \\
\hline Grade I & $134(45.7)$ \\
\hline Grade II & $2(0.7)$ \\
\hline Grade III & $34(11.6)$ \\
\hline Grade IV & $35(11.9)$ \\
\hline Operation time (min) & $71.23 \pm 32.61$ \\
\hline Estimated blood loss (mL) & $138.96 \pm 123.52$ \\
\hline \multicolumn{2}{|c|}{ Conversion to other operation type } \\
\hline None & $292(99.7)$ \\
\hline Two ports & 0 \\
\hline Three ports & 0 \\
\hline Laparotomy & $1(0.3)$ \\
\hline Hemoglobin drop (g/dL) & $1.33 \pm 0.78$ \\
\hline Hematocrit drop (\%) & $4.14 \pm 2.45$ \\
\hline \multicolumn{2}{|l|}{ Complications } \\
\hline Transfusion & $10(3.4)$ \\
\hline Bladder injury & 0 \\
\hline Bowel injury & 0 \\
\hline Postoperative fever & 0 \\
\hline Intraperitoneal hematoma & $6(2.0)$ \\
\hline Reoperation & 0 \\
\hline \multicolumn{2}{|c|}{ Postoperative hospital stay (day) } \\
\hline$\leq 7$ & $275(93.9)$ \\
\hline $8-10$ & $11(3.8)$ \\
\hline $11-14$ & $6(2.0)$ \\
\hline$\geq 15$ & $1(0.3)$ \\
\hline \multicolumn{2}{|l|}{ Histology } \\
\hline Mature cystic teratoma & $98(33.4)$ \\
\hline Endometriosis & $68(23.2)$ \\
\hline Cystadenoma & $52(17.7)$ \\
\hline Carcinoma & $4(1.4)$ \\
\hline Others ${ }^{\text {a) }}$ & $69(23.5)$ \\
\hline
\end{tabular}

Values are presented as mean \pm standard deviation or number (\%).

${ }^{a}$ Benign simple cyst, corpus luteal hemorrhagic cyst, pseudocyst, abscess, fibroma, sex cord tumor, and germ cell tumor.

tion; one had a history of diagnostic laparoscopy; and eight women had undergone other abdominal surgery. A majority of the patients had myomas in more than one location $(n=227,92.3 \%)$, as well as 14 cases of isolated intramural myomas (5.7\%), two cases of isolated subserosal myomas $(0.8 \%)$, and three cases of isolated submucosal myomas (1.2\%).

The results of SPA laparoscopic ovarian cystectomy are presented in Table 3.

For hemostasis, interrupted sutures were performed in 173 patients (59.0\%), while continuous sutures were performed in 120 patients 


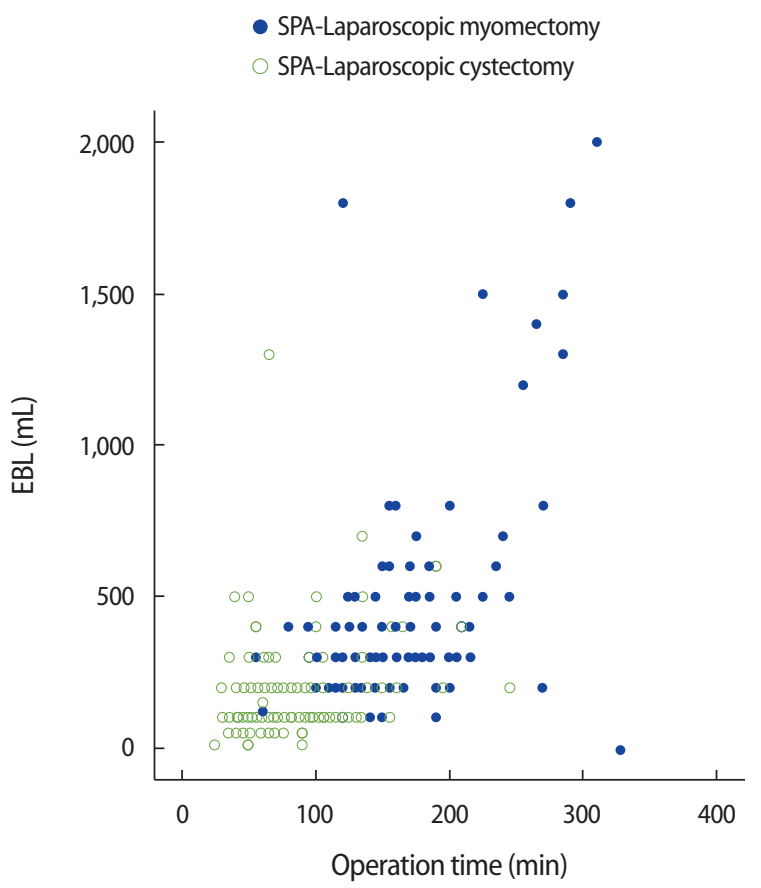

Figure 3. Correlations between operation time and amount of estimated blood loss (EBL) in single-port access (SPA) laparoscopic cystectomy and SPA laparoscopic myomectomy. The Pearson correlation coefficient and Spearman correlation coefficient between the operative time and the amount of EBL were 0.312 and 0.321 for SPA laparoscopic cystectomy and 0.706 and 0.674 for SPA laparoscopic myomectomy, respectively; both were statistically significant.

(41.0\%). The mean operative time was $71.23 \pm 32.61$ minutes and the estimated blood loss (EBL) was $138.96 \pm 123.52 \mathrm{~mL}$. The Pearson correlation coefficient between the duration of the operation and the EBL was 0.312, and the Spearman correlation coefficient was 0.321. Both correlations were statistically significant (Figure 3).

Mild adhesion was found in the mesentery in 134 patients (45.7\%), and adhesion between the adnexa and the intestine was seen in 34 patients (11.6\%). Severe adhesion with complete obliteration of the Douglas pouch was observed in 35 patients (11.9\%). No cases required conversion to multi-port laparoscopic surgery, but one case was converted to open surgery. The drop in the plasma hemoglobin level from before surgery to after surgery was $1.33 \pm 0.78 \mathrm{~g} / \mathrm{dL}$, and the drop in hematocrit was $4.14 \% \pm 2.45 \%$. Ten women (3.4\%) required transfusion, and intra-abdominal hemorrhage occurred in six cases (2.0\%), but none required reoperation. The final pathological reports included the following findings: mature cystic teratoma $(n=98,33.4 \%)$, endometrioma $(n=68,23.2 \%)$, serous and/or mucinous cystadenoma $(n=52,17.7 \%)$, and malignancy $(n=4,1.4 \%)$. The remaining 69 patients (23.5\%) were diagnosed with a fibroma, sex cord stromal tumor, simple cyst, or hemorrhagic corpus luteum. In 275 patients (93.9\%), the hospital stay was 7 days or less.
Table 4. Clinical outcomes of single-port access laparoscopic myomectomy

\begin{tabular}{|c|c|}
\hline Clinical outcome & Variable \\
\hline No. of myomas resected by myomectomy (range) & $2.31 \pm 2.39(1-15)$ \\
\hline Size of myoma (cm) & $5.11 \pm 2.11$ \\
\hline \multicolumn{2}{|l|}{ Adhesion degree } \\
\hline Grade I & $142(57.7)$ \\
\hline Grade II & $3(1.2)$ \\
\hline Grade III & $12(4.9)$ \\
\hline Grade IV & $19(7.7)$ \\
\hline \multicolumn{2}{|l|}{ Procedure } \\
\hline Myomectomy, one myoma & $47(19.1)$ \\
\hline Myomectomy, multiple myoma & $175(71.1)$ \\
\hline Myomectomy with adnexal surgery & $24(9.8)$ \\
\hline \multicolumn{2}{|l|}{ Morcellation type } \\
\hline \multicolumn{2}{|l|}{ None } \\
\hline With electrical morcellator & $1(0.04)$ \\
\hline Through umbilical incision site without bag & $235(95.5)$ \\
\hline Through umbilical incision site with bag & $10(4.06)$ \\
\hline \multicolumn{2}{|l|}{ Suture method } \\
\hline Interrupted & $160(65.0)$ \\
\hline Continuous locking & $86(35.0)$ \\
\hline Operation time (min) & $107.68 \pm 50.61$ \\
\hline Estimated blood loss (mL) & $263.67 \pm 258.93$ \\
\hline \multicolumn{2}{|l|}{ Conversion to other operation type } \\
\hline None & $243(98.8)$ \\
\hline Two or three ports & $1(0.8)$ \\
\hline Laparotomy & $1(0.4)$ \\
\hline \multicolumn{2}{|l|}{ Uterine cavity penetration } \\
\hline No & $243(98.8)$ \\
\hline Yes & $3(1.2)$ \\
\hline Hemoglobin drop (g/dL) & $1.34 \pm 1.13$ \\
\hline Hematocrit drop (\%) & $4.17 \pm 3.24$ \\
\hline \multicolumn{2}{|l|}{ Complications } \\
\hline Transfusion & $29(11.8)$ \\
\hline Bladder injury & 0 \\
\hline Bowel injury & $1(0.04)$ \\
\hline Postoperative fever & $12(4.9)$ \\
\hline Intraperitoneal hematoma & $3(1.2)$ \\
\hline Reoperation & 0 \\
\hline \multicolumn{2}{|l|}{ Postoperative hospital stay (day) } \\
\hline$\leq 7$ & $229(93.0)$ \\
\hline $8-10$ & $16(6.5)$ \\
\hline $11-14$ & $1(0.04)$ \\
\hline$\geq 15$ & 0 \\
\hline
\end{tabular}

Values are presented as mean \pm standard deviation or number (\%).

The results of SPA laparoscopic myomectomy are shown in Table 4.

The mean number of myomas removed was $2.31 \pm 2.39$ (range, $1-15)$, excluding those smaller than $1 \mathrm{~cm}$. The size of the myoma was determined by its greatest diameter, and the mean size was $5.11 \pm 2.11 \mathrm{~cm}$. A morcellator was used in only one case, while in most cases $(n=235,95.5 \%)$, the myomas were removed through the 
single port after dissection with surgical blades. In 10 women, myomas that contained degenerative portions were removed using the Endopouch specimen retrieval bag (Ethicon).

After removing the myomas close to the endometrium, interrupted figure-of-eight sutures were performed in the deep layer. Excluding the sutures in this layer, 160 cases had interrupted sutures, and 86 cases had continuous sutures. In 175 women (71.1\%), multiple myomectomy was performed, whereas in 47 women (19.1\%), a single large myoma was removed. Additional adnexal surgery was performed in 24 women (9.8\%), and in 142 women, mild adhesion with the mesentery was found. In 19 women (7.7\%), dense adhesion with the intestine was found, and some required collaborative treatment with a general surgeon. The mean operation time was $107.68 \pm 50.61 \mathrm{~min}-$ utes, and the EBL was $263.67 \pm 258.93 \mathrm{~mL}$. The Pearson correlation coefficient between the operation time and EBL was 0.706 and the Spearman correlation coefficient was 0.674 ; both correlations were found to be statistically significant (Figure 3). Two cases required conversion to multi-port laparoscopic surgery, and one case required open surgery. The endometrium was exposed in three cases (1.2\%). The drop in plasma hemoglobin level after surgery was $1.34 \pm 1.13 \mathrm{~g} / \mathrm{dL}$, and the drop in plasma hematocrit levels was $4.17 \% \pm 3.24 \%$. Transfusion was required in 29 patients (11.8\%), and three patients (1.2\%) experienced intra-abdominal hemorrhage, but none required reoperation. In 229 patients (93.0\%), the hospital stay was 7 days or less.

\section{Discussion}

In order to maximize the advantages of minimally invasive surgery, a technique has been introduced in which only one port is used for entry. This technique is known as single-incision laparoscopy, and is also referred to as laparoscopic single-site surgery, single-port access, and single-incision laparoscopic surgery. After this technique was first used for appendectomy in 2005, it has been implemented in urology, gynecology, and general surgery. Many types of single-port laparoscopic instruments have been developed with swiveling and bending abilities. Recently, surgical techniques using the traditional straight instruments have also been developed [12]. Tam et al. [13] reported no difference when using two straight instruments crossing each other in an SPA technique compared to conventional laparoscopy, while in another study, changing the Z-axis by using rotating curved instruments and altering their length was found to be useful in preventing crowding and to make more room for triangulation [14]. In the early days of SPA, we used curved instruments in our facility, but later transitioned to using straight instruments. Straight instruments can resist more tension, and are associated with less need to change instruments, and therefore with reduced operation time.

SPA ovarian cystectomy was first performed by Kosumi et al. [15] in
2001. In 2009, Fagotti et al. [16] reported three cases of ovarian cystectomy in which this technique was used, thereby proving it useful. In 2011, Fagotti et al. [11] reported that SPA laparoscopic surgery had the benefit of reduced postoperative pain compared to conventional laparoscopic surgery. Extended operative time is one of the critical issues with the SPA technique, but Lee et al. [17] reported that the operative times for SPA and conventional laparoscopic surgery were 64 minutes and 57.5 minutes, respectively, which was not a statistically significant difference $(p=0.252)$. Park et al. [18] found operative times of 60 minutes (range, 27-245 minutes), 105 minutes (range, 50-185 minutes), and 60 minutes (range, 30-115 minutes) for SPA oophorectomy, ovarian cystectomy, and salpingectomy, respectively. In our study, the average operative time was 71.23 minutes for SPA ovarian cystectomy, and the EBL was $138.96 \mathrm{~mL}$. The operative time and EBL were significantly correlated, with a Pearson correlation coefficient of 0.312 and a Spearman correlation coefficient of 0.321 (Figure 3).

The upward trend of age at marriage and the increase in infertility associated with myomas have resulted in an increase in the conservative treatment of this condition [19]. In cases of myomas that cause a distortion in the endometrial cavity lining, myomectomy can help increase the pregnancy rates $[9,10]$, and no increase in pregnancy complications was found following myomectomy [20,21].

Kim et al. [22] found that the mean weight of myomas in SPA laparoscopic myomectomy was $55.4 \pm 54.7 \mathrm{~g}$ and that the mean operative time was $68.7 \pm 32$ minutes. Kim et al. [23] reported in 2014 that the mean weight of myomas was $173.9 \pm 160.0 \mathrm{~g}$, the operative time was $115.7 \pm 45.8$ minutes, 42 patients $(76.4 \%)$ had only one myoma, and 13 patients (23.6\%) had two myomas in the SPA laparoscopy group. In the conventional laparoscopy group, the mean weight of myomas was $126.8 \pm 97.0 \mathrm{~g}$, the operative time was $128.2 \pm 35.7$ minutes, 64 patients (62.7\%) had one myoma, and 38 patients (37.3\%) had two myomas. No significant difference was found in the operative time between SPA and conventional laparoscopic surgery.

In our study, the mean size of the myomas was $5.11 \mathrm{~cm}$, and the mean operative time was 107.68 minutes. The operative time was relatively long because $71.7 \%$ of cases were multiple myomectomies, with a mean of $2.31 \pm 2.39$ myomas (range, 1-15). The operative time was significantly related to the size of the myomas, with a Pearson correlation coefficient of 0.245 and a Spearman correlation coefficient of 0.245 . The association between the EBL and the size of the myomas was also significant, with a Pearson correlation coefficient of 0.222 and a Spearman correlation coefficient of 0.259 . Larger myomas were associated with increased operative time and EBL to a statistically significant extent.

In this study, we describe our experience with SPA laparoscopic ovarian cystectomy and myomectomy. No differences were found between this technique and conventional laparoscopic surgery in 
terms of surgical results. This technique was superior in relieving postoperative pain, led to better cosmetic results, and can be expected to become more popular in the near future. We also found that using conventional straight instruments in SPA laparoscopic surgery can produce comparable results to the use of curved instruments. However, a prospective controlled study of SPA techniques by a single experienced surgeon would yield better results, and further research into the advantages and disadvantages of this technique is needed, especially with regard to postoperative adhesion and future pregnancies.

\section{Conflict of interest}

No potential conflict of interest relevant to this article was reported.

\section{References}

1. Buttram VC Jr, Reiter RC. Uterine leiomyomata: etiology, symptomatology, and management. Fertil Steril 1981;36:433-45.

2. Hasson HM, Rotman C, Rana N, Sistos F, Dmowski WP. Laparoscopic myomectomy. Obstet Gynecol 1992;80:884-8.

3. Dubuisson JB, Fauconnier A, Chapron C, Kreiker G, Norgaard C. Reproductive outcome after laparoscopic myomectomy in infertile women. J Reprod Med 2000;45:23-30.

4. Kalogiannidis I, Lambrechts S, Amant F, Neven P, Van Gorp T, Vergote I. Laparoscopy-assisted vaginal hysterectomy compared with abdominal hysterectomy in clinical stage I endometrial cancer: safety, recurrence, and long-term outcome. Am J Obstet Gynecol 2007;196:248.e1-8.

5. Walker JL, Piedmonte MR, Spirtos NM, Eisenkop SM, Schlaerth JB, Mannel RS, et al. Laparoscopy compared with laparotomy for comprehensive surgical staging of uterine cancer: Gynecologic Oncology Group Study LAP2. J Clin Oncol 2009;27:5331-6.

6. Jin C, Hu Y, Chen XC, Zheng FY, Lin F, Zhou K, et al. Laparoscopic versus open myomectomy: a meta-analysis of randomized controlled trials. Eur J Obstet Gynecol Reprod Biol 2009;145:14-21.

7. Oliveira FG, Abdelmassih VG, Diamond MP, Dozortsev D, Melo $\mathrm{NR}$, Abdelmassih R. Impact of subserosal and intramural uterine fibroids that do not distort the endometrial cavity on the outcome of in vitro fertilization-intracytoplasmic sperm injection. Fertil Steril 2004;81:582-7.

8. Bulletti C, DE Ziegler D, Levi Setti P, Cicinelli E, Polli V, Stefanetti M. Myomas, pregnancy outcome, and in vitro fertilization. Ann NY Acad Sci 2004;1034:84-92.

9. Kim YW. Single port transumbilical total laparoscopic hysterectomy (TLH): initial experience in Korea. Korean J Obstet Gynecol 2009:52:480-6.
10. Yoon BS, Park H, Seong SJ, Park CT, Park SW, Lee KJ. Single-port laparoscopic salpingectomy for the surgical treatment of ectopic pregnancy. J Minim Invasive Gynecol 2010;17:26-9.

11. Fagotti A, Bottoni C, Vizzielli G, Gueli Alletti S, Scambia G, Marana $E$, et al. Postoperative pain after conventional laparoscopy and laparoendoscopic single site surgery (LESS) for benign adnexal disease: a randomized trial. Fertil Steril 2011;96:255-9.e2.

12. Paek J, Nam EJ, Kim YT, Kim SW. Overcoming technical difficulties with single-port access laparoscopic surgery in gynecology: using conventional laparoscopic instruments. J Laparoendosc Adv Surg Tech A 2011;21:137-41.

13. Tam YH, Lee KH, Sihoe JD, Chan KW, Cheung ST, Pang KK. Initial experience in children using conventional laparoscopic instruments in single-incision laparoscopic surgery. J Pediatr Surg 2010;45:2381-5.

14. Podolsky ER, Curcillo PG 2nd. Single port access (SPA) surgery: a 24-month experience. J Gastrointest Surg 2010;14:759-67.

15. Kosumi T, Kubota A, Usui N, Yamauchi K, Yamasaki M, Oyanagi H. Laparoscopic ovarian cystectomy using a single umbilical puncture method. Surg Laparosc Endosc Percutan Tech 2001;11:63-5.

16. Fagotti A, Fanfani F, Marocco F, Rossitto C, Gallotta V, Scambia G. Laparoendoscopic single-site surgery (LESS) for ovarian cyst enucleation: report of first 3 cases. Fertil Steril 2009;92:1168.e13-6.

17. Lee YY, Kim TJ, Kim CJ, Park HS, Choi CH, Lee JW, et al. Single port access laparoscopic adnexal surgery versus conventional laparoscopic adnexal surgery: a comparison of peri-operative outcomes. Eur J Obstet Gynecol Reprod Biol 2010;151:181-4.

18. Park SN, Hong GY, Kim HY, Kim BR, Lee C. A comparison of single-port laparoscopically assisted vaginal hysterectomy using transumbilical sils port access and three-port laparoscopically assisted vaginal hysterectomy. Korean J Obstet Gynecol 2012; 55:22-8.

19. Alessandri F, Lijoi D, Mistrangelo E, Ferrero S, Ragni N. Randomized study of laparoscopic versus minilaparotomic myomectomy for uterine myomas. J Minim Invasive Gynecol 2006;13:92-7.

20. Yoo EH, Kim D. Obstetric outcomes after laparoscopic myomectomy. Korean J Obstet Gynecol 2008;51:1481-6.

21. Leggett PL, Churchman-Winn R, Miller G. Minimizing ports to improve laparoscopic cholecystectomy. Surg Endosc 2000;14: 32-6.

22. Kim IH, Lee GH, Yi HJ, Lee YJ, Na ED. Single port access laparoscopic myomectomy. Korean J Gynecol Endosc Minim Invasive Surg 2011;23:14-8

23. Kim SK, Lee JH, Lee JR, Suh CS, Kim SH. Laparoendoscopic single-site myomectomy versus conventional laparoscopic myomectomy: a comparison of surgical outcomes. J Minim Invasive Gynecol 2014;21:775-81. 